\title{
Mechanistic Study on Gold-Like Luster Development of Solution-Cast Oligo(3-methoxythiophene) Film
}

\author{
Minako Kubo ${ }^{1}$, Minako Tachiki ${ }^{1}$, Terumasa Mitogawa ${ }^{1}$, Kota Saito ${ }^{1}$, Ryota Saito ${ }^{1}$, Satoru Tsukada ${ }^{1}{ }^{\mathbb{D}}$, \\ Takahiko Horiuchi ${ }^{2}$ (D) and Katsuyoshi Hoshino ${ }^{1, *}$ \\ 1 Department of Materials Science, Graduate School of Engineering, Chiba University, 1-33 Yayoi-cho, Inage-ku, \\ Chiba 263-8522, Japan; qminako@yahoo.co.jp (M.K.); m_maruo@chiba-u.jp (M.T.); \\ goemonn29@gmail.com (T.M.); kota.saito0107@gmail.com (K.S.); kp.ryo007@chiba-u.jp (R.S.); \\ tsukada@chiba-u.jp (S.T.) \\ 2 Department of Imaging Sciences, Graduate School of Engineering, Chiba University, 1-33 Yayoi-cho, Inage-ku, \\ Chiba 263-8522, Japan; horiuchi@faculty.chiba-u.jp \\ * Correspondence: k_hoshino@faculty.chiba-u.jp
}

Citation: Kubo, M.; Tachiki, M.; Mitogawa, T.; Saito, K.; Saito, R.; Tsukada, S.; Horiuchi, T.; Hoshino, K. Mechanistic Study on Gold-Like Luster Development of Solution-Cast Oligo(3-methoxythiophene) Film. Coatings 2021, 11, 861. https:// doi.org/10.3390/coatings11070861

Academic Editor: Gianni Barucca

Received: 18 June 2021

Accepted: 15 July 2021

Published: 18 July 2021

Publisher's Note: MDPI stays neutral with regard to jurisdictional claims in published maps and institutional affiliations.

Copyright: (C) 2021 by the authors. Licensee MDPI, Basel, Switzerland. This article is an open access article distributed under the terms and conditions of the Creative Commons Attribution (CC BY) license (https:// creativecommons.org/licenses/by/ $4.0 /)$

\begin{abstract}
Solution-cast coating films of perchlorate-doped oligo(3-methoxythiophene) exhibited a gold-like luster similar to that of metallic gold despite the involvement of no metals. However, the development mechanism of the luster remains ambiguous. To understand the mechanism, we performed scanning electron microscopic analysis, variable-angle spectral reflectance measurements, and ellipsometry measurements on $\mathrm{ClO}_{4}{ }^{-}$-doped oligo(3-methoxythiophene) cast film with a goldlike luster. The results revealed that the lustrous color of the film was not induced by the submicronsized regular structures (structural color), nor by the high-density free electrons (reflective response based on Drude model), but by the large optical constants (refractive index and extinction coefficient) of the film, as speculated previously.
\end{abstract}

Keywords: decorative coating; oligothiophene; gold-like luster; solution cast film; lamellar structure; optical constants; gloss mechanism

\section{Introduction}

Poly(3-alkylthiophene)s and oligo(3-alkylthiophene)s with an alkyl group at the 3position have attracted wide-spread attention as materials with potential applications in organic field-effect transistors [1-3], light-emitting diodes [4,5], and photovoltaic cells [6,7]. This is based on the facts that the above thiophene compounds are chemically and electrochemically stable, and that lamellar crystallites are formed through $\pi-\pi$ stacking interactions within their solids. In addition, an important property comparable to such high stability and crystallinity is that poly(3-alkylthiophene)s and oligo(3-alkylthiophene)s are soluble in organic solvents, such as chloroform, and can be applied to a variety of substrates to yield coating films $[8,9]$.

On the other hand, we have chemically synthesized anion-doped oligo(3-methox ythiophene) (O3MeOT) featuring a methoxy group at the 3-position [10-14], and found that its coating films develop gold-like colors unlike poly(3-alkylthiophene)s and oligo(3alktlthiophene)s. Subsequently, from X-ray diffraction (XRD) patterns and ellipsometry measurements of the films, we inferred that the gold tone coloration was due to edge-on lamellar crystallites formed by the orientation of thiophene rings perpendicular to the substrate. Specifically, it was speculated that the films have an ability to reflect light due to the large optical constants (refractive index and extinction coefficient) of the edge-on lamellar crystallites in films, exhibiting a gold-like luster. However, it is known that there are two other possible reasons for a material to develop luster. The first is the reflection of light based on Drude metallic response [15], and second is light diffraction/interference (structural colors) due to the regular structure of the materials at the visible light wavelength 
range $[16,17]$. Therefore, to clarify the origin of the luster development in the O3MeOT films, it is required to investigate the contribution of the above two reasons. In the research field of texture, gold is a specific color, and it is very important to understand the mechanism of gold coloration in color engineering $[18,19]$. In this study, we carried out the cross-sectional morphology, variable-angle spectral reflectance, and optical constant spectra measurements of the O3MeOT film, and evaluated the origin of its luster. The results of the evaluation are described as follows.

\section{Materials and Methods}

\subsection{Materials}

3-Methoxythiophene ( $>98 \%$; Fujifilm Wako Pure Chemical Co., Tokyo, Japan) was polymerized by oxidation with $\mathrm{Fe}\left(\mathrm{ClO}_{4}\right)_{3} \cdot n \mathrm{H}_{2} \mathrm{O}$ (anhydrous salt content $=70.7 \%$; Fujifilm Wako Pure Chemical). Acetonitrile (>99.7\%; Kanto Chemical, Tokyo Japan), nitromethane (>98.0\%; Tokyo Chemical Industry, Tokyo, Japan), and methanol (99.8\%; Kanto Chemical) were used as supplied. O3MeOT was prepared as reported elsewhere [10]. The procedure is briefly discussed here. A solution of 3-methoxythiophene $(0.123 \mathrm{~g})$ in acetonitrile $(10 \mathrm{~mL})$ was placed in a glass cell and de-aerated for $30 \mathrm{~min}$ with nitrogen gas bubbling through the solution upon stirring at $350 \mathrm{rpm}$. This solution was instantaneously supplemented with a solution of $\mathrm{Fe}\left(\mathrm{ClO}_{4}\right)_{3} \cdot n \mathrm{H}_{2} \mathrm{O}(1.10 \mathrm{~g})$ in acetonitrile $(10 \mathrm{~mL})$ prepared by ultrasonication for $20 \mathrm{~min}$. The resulting solution was stirred at $20^{\circ} \mathrm{C}$ for $60 \mathrm{~min}$ and suction-filtered through a membrane filter (pore size $=0.1 \mu \mathrm{m}$ ). The filter cake was washed vigorously with methanol at least three times, and the resulting deep blue powder was vacuum-dried at $50{ }^{\circ} \mathrm{C}$ for $1.5 \mathrm{~h}$ to yield $\mathrm{ClO}_{4}{ }^{-}$-doped O3MeOT. The molecular weight and perchlorate doping level of O3MeOT were $1.14 \times 10^{3}$ and 30\%, respectively (see reference [13] and its Supporting Information). The glass plate (S1225, Matsunami Glass, Osaka, Japan) was cleaned by 10 -min sonication in acetone $(>99.5 \%$; Kanto Chemical) prior to use.

\subsection{Coating Solution and Film Preparation}

A coating solution was prepared by dissolving O3MeOT $(0.010 \mathrm{~g})$ in nitromethane $(0.99 \mathrm{~g}, 0.87 \mathrm{~mL})$ and the solution was stirred at $22{ }^{\circ} \mathrm{C}$ for $90 \mathrm{~min}$. The resulting solution was aged for one day [11] and applied to a glass plate $(100 \mathrm{~mm} \times 100 \mathrm{~mm} \times 1.1 \mathrm{~mm})$ by the bar coating method with a 5-mm-diameter Teflon rod. This was dried under ambient conditions to afford a film. The quantity of the applied solution was $2500 \mu \mathrm{L}$. In our previous studies, O3MeOT films of $15 \times 25 \mathrm{~mm}^{2}$ in size have been prepared by the dip coating method. However, in this study, a large-area film was required for the variableangle spectral reflectance measurements; therefore, the film was prepared using the bar coating method. From the cross-sectional image of the film shown later, the film thickness was determined to be $2.1 \mu \mathrm{m}$.

\subsection{Instrumentation and Method of Film Characterization}

The cross section of the O3MeOT film was observed using a scanning electron microscope (JSM-6700F, JEOL, Tokyo, Japan). Variable-angle spectral reflectance measurements were carried out using a goniospectrometer (GCMS-4, Murakami Color Research Laboratory, Tokyo, Japan). Optical constants of the film were measured using a variable-angle spectroscopic ellipsometer (alpha-SE, J. A. Woollam Co., Lincoln, NE, USA) which covers $380-900 \mathrm{~nm}$ and permits a scanning of the incident angle from $65^{\circ}$ to $75^{\circ}$ with an accuracy of $0.01^{\circ}$. Ellipsometric data were fitted using the J. A. Woolam CompleteEASE software version 6.37 .

\section{Results and Discussion}

\subsection{Appearance and Morphology of a Coating Film}

Figure 1 shows a photograph and scanning electron microscopy (SEM) images of an O3MeOT film coated on a glass substrate. The surface of the film depicts the reflected images of letters and rulers placed perpendicular to the film, indicating the specular 
reflection property. The reflection spectrum of the bar-coated film of O3MeOT in the present study (Supplementary Figure S1) agrees in intensity and shape with the previously reported reflection spectrum of the drop-cast film [11-13]. Therefore, these two films are considered to be optically identical. In the SEM image of the cross-section of the film (Figure $1 b$ ) and its partially enlarged image (Figure 1c), no layered or lattice submicron structure causing light interference or submicron structure causing Tyndall scattering was observed. These observations reduced the possibility that structural color is the origin of the film gloss.

(a)

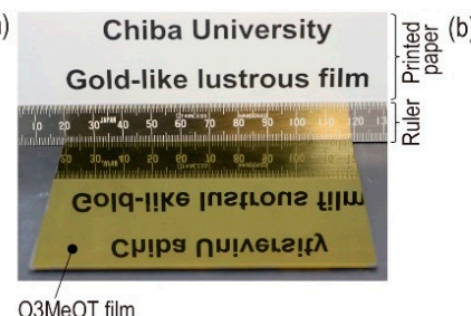

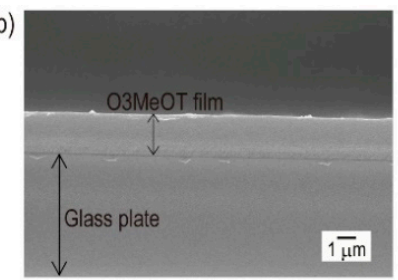

(c)

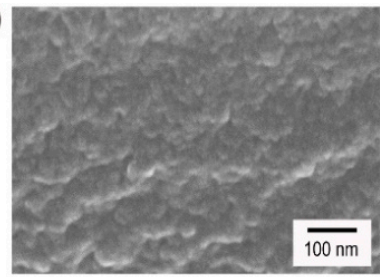

Figure 1. Photograph (a) and cross-sectional SEM images $(\mathbf{b}, \mathbf{c})$ of the O3MeOT film.

\subsection{Variable-Angle Spectral Reflectance Measurements}

Subsequently, the possibility of the origin of a structural color was examined from the spectroscopic perspective. Figure 2 presents the schematic of a goniometric system for measuring spectral reflectance. The incident light angles, $\theta_{i}$, with respect to the normal of the film surface, were $15^{\circ}, 30^{\circ}, 45^{\circ}, 60^{\circ}$, and $75^{\circ}$. The detection angle $\theta_{r}$ of the reflected light was set in the range of $-80^{\circ}$ to $80^{\circ}$ at $5^{\circ}$ intervals. The O3MeOT film is considered to have a strong specular reflection component based on the results in Figure 1a, therefore, the measurements were performed at $1^{\circ}$ intervals in the range of $10^{\circ}$ before and after the specular reflection angle. In these measurements, a barium sulfate plate was used as the reference material, and thus the measured reflection intensity of the O3MeOT film is the relative reflection intensity to that of barium sulfate.

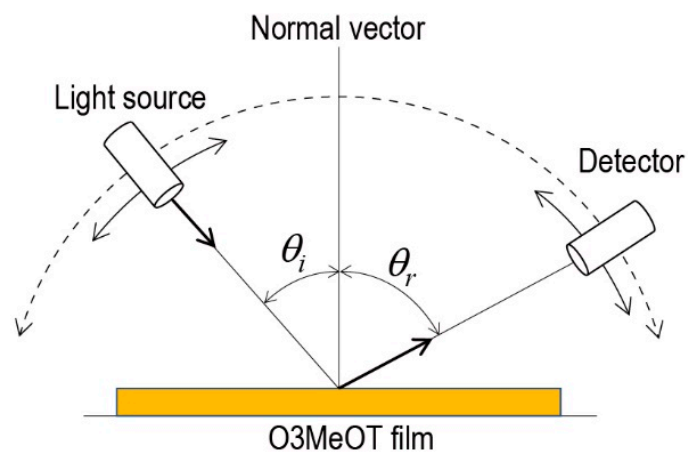

Figure 2. A schematic of the instrumental setup for variable-angle spectral reflectance measurements of the O3MeOT film.

Figure 3 depicts the $\theta_{i}$ and $\theta_{r}$ dependences of the reflection spectra of the O3MeOT film. First, $\theta_{i}$ was fixed and the specular reflection spectra were recorded while $\theta_{r}$ was changed. Then, $\theta_{i}$ was changed and the spectra were measured in the same way to obtain the spectra shown in Figure 3. For any incidence angle $\theta_{i}$, the reflectance was maximum when the relationship $\theta_{i}=\theta_{r}$ was satisfied (i.e., specular reflection condition), and no light reflection occurred in cases where $\theta_{r}>\theta_{i}+2^{\circ}$ or $\theta_{r}<\theta_{i}-2^{\circ}$. For each incidence angle $\theta_{i}$, the reflection spectra satisfying $\theta_{i}=\theta_{r}$ (i.e., the specular reflection spectra) were extracted from Figure 3 and compared as shown in Figure 4a. Assuming that barium sulfate is a perfect reflecting diffuser, according to Lambert's cosine law [20], the luminous intensity $I_{\theta r}$ of the reflected light from the barium sulfate surface at $\theta_{r}$ is given by Equation (1). 
(a)

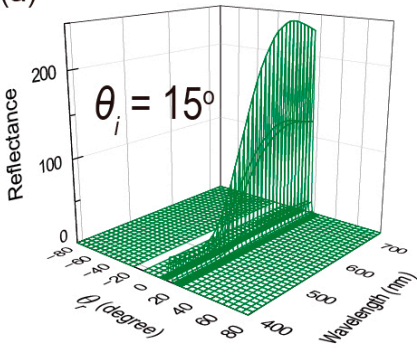

(c)

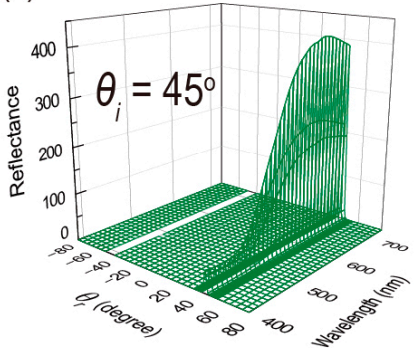

(b)

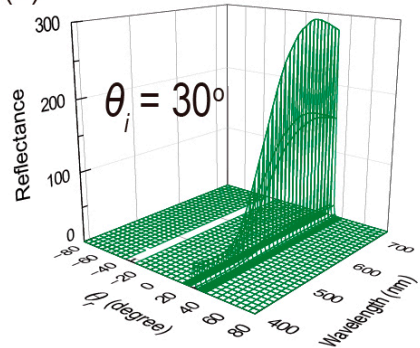

(d)

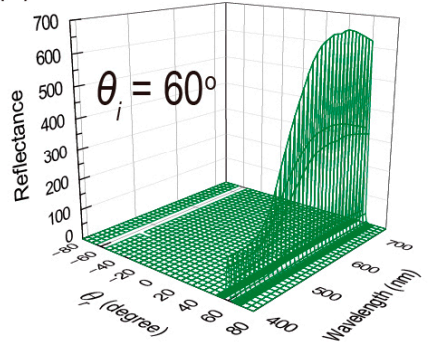

(e)

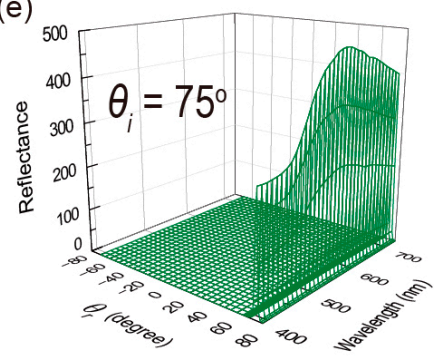

Figure 3. Reflection spectra of the O3MeOT film measured as a function of detection angle, $\theta_{r}$. Incident light angle, $\theta_{i}:(\mathbf{a}), 15^{\circ} ;(\mathbf{b}), 30^{\circ} ;(\mathbf{c}), 45^{\circ} ;(\mathbf{d}), 60^{\circ} ;(\mathbf{e}), 75^{\circ}$.

$$
I_{\theta r}=I_{n} \cdot \cos \theta_{r}
$$

where $I_{n}$ is the luminous intensity at $\theta_{r}=0^{\circ}$. The reflectance value of the O3MeOT film in Figure $4 \mathrm{a}$ is the specular reflection luminous intensity of the O3MeOT film with reference to $I_{\theta r}$. However, it is not desirable to use $I_{\theta r}$ as a reference value since the reference luminous intensity is a function of $\theta_{r}$. Therefore, the reflectance value in Figure $4 \mathrm{a}$ was multiplied by $\cos \theta_{r}$ and corrected to the relative reflectance value with reference to $I_{n}$ (Figure $4 \mathrm{~b}$ ). The reflection spectrum of a vacuum-evaporated gold film on a glass plate is also shown for comparison (Figure 4c,d). In the corrected spectra (Figure 4b,d), the spectra were approximately equal in reflection intensity and shape when the spectra were measured at angles $\theta_{r}\left(=\theta_{i}\right)=15^{\circ}, 30^{\circ}$, and $45^{\circ}$. However, at $\theta_{r}=60^{\circ}$ and $75^{\circ}$, the spectral shapes were comparable, but the reflection intensities were different from the above spectra. This is probably because the barium sulfate surface is not a perfect reflecting diffuser [21], and larger deviations may occur at larger $\theta_{r}$. In the case of the O3MeOT film (Figure $4 \mathrm{~b}$ ), the maximum reflection intensities at angles $\theta_{r}\left(=\theta_{i}\right)=60^{\circ}$ and $75^{\circ}$ were deviated by about $30 \%$ and $56 \%$, respectively, compared to those at $\theta_{r}\left(=\theta_{i}\right)=30^{\circ}$. Also, for the vacuumevaporated gold film (Figure $4 \mathrm{~d}$ ), the maximum reflection intensities at angles $\theta_{r}\left(=\theta_{i}\right)=60^{\circ}$ and $75^{\circ}$ were deviated by about $20 \%$ and $86 \%$, respectively, compared to those at $\theta_{r}\left(=\theta_{i}\right)$ $=30^{\circ}$. Aside from these reflection intensity issues, it is important to note that the shape of the specular reflection spectrum is approximately the same regardless of $\theta_{r}$, i.e., the reflection color of the film does not change with $\theta_{r}$. In the case of many materials having structural colors, it is known that they exhibit different colors depending on the value of $\theta_{r}$ [22-26]. In other words, the reflection spectrum shows a $\theta_{r}$-dependence when $\theta_{i}$ is 
constant. Therefore, it can be concluded that the lustrous color of the O3MeOT film, which has no viewing angle dependence, is not based on the color development mechanism by structural color. In some other metal-free organic glossy materials, similar variableangle spectral reflectance measurements have been performed to prove that their gloss is not based on the structural color $[27,28]$. On the other hand, there are some reports of $\theta_{r}$-independent structural colors $[29,30]$. In this case, however, submicron-sized particles or pores are required to be distributed in a short-range order. As can be observed from the SEM image in Figure 1b,c, no such structure was found in the O3MeOT film, indicating that its lustrous color is not due to the $\theta_{r}$-independent structural color either.

(a)

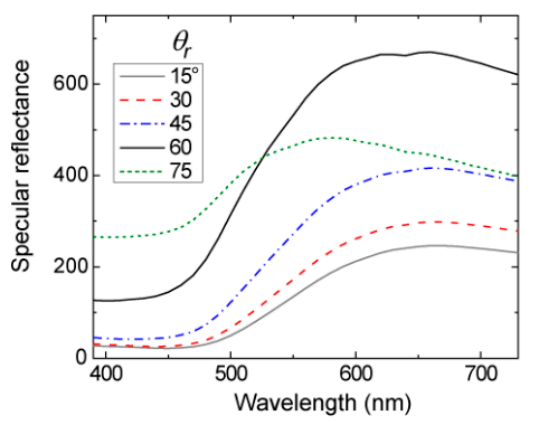

(c)

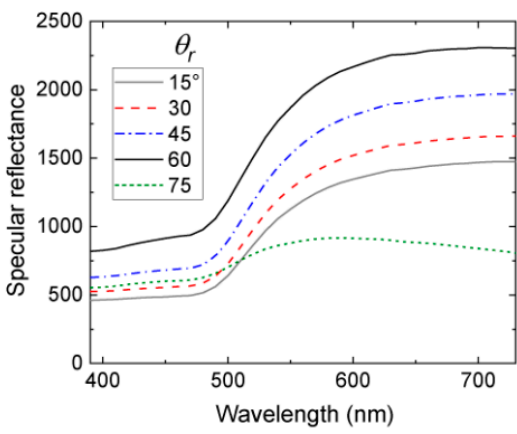

(b)

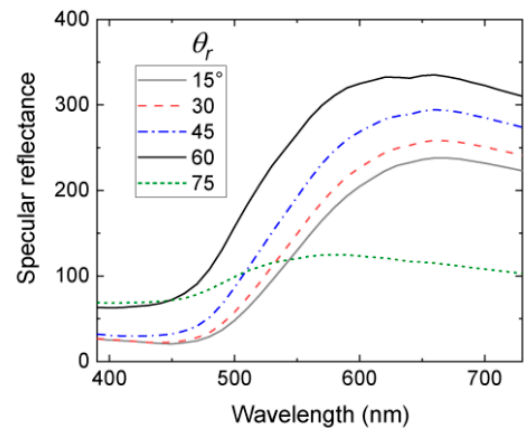

(d)

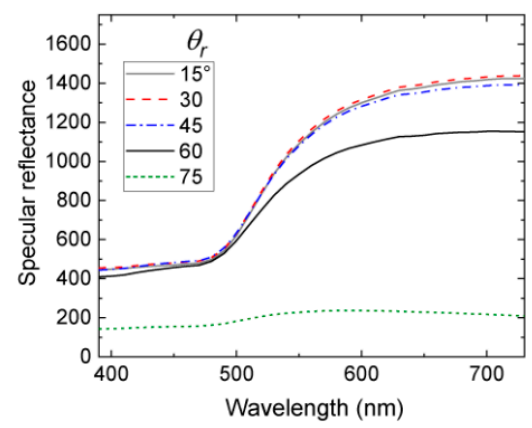

Figure 4. Specular reflection spectra of O3MeOT film before correction (a); O3MeOT film after correction (b); vacuum-evaporated gold film before correction (c); vacuum-evaporated gold film after correction (d) by Lambert's cosine law.

\subsection{Ellipsometry Measurements}

The refractive index $(n)$ spectra and extinction coefficient $(\kappa)$ spectra of the O3MeOT and vacuum-evaporated gold films obtained by ellipsometry are shown in Figure 5 . The peak position of the refractive index spectrum of the O3MeOT film was located at a longer wavelength than the peak position of the corresponding extinction coefficient spectrum. This is due to the wavelength dispersion of the collective velocity of light in typical dielectrics [31]. As shown in Equation (2), the specular reflectance $(R)$ depends on $n$ and $\kappa$, and the $R$ value is positively correlated with both $n$ and $\kappa[11,13,14,27]$.

$$
R=\frac{(n-1)^{2}+\kappa^{2}}{(n+1)^{2}+\kappa^{2}}
$$


(a)

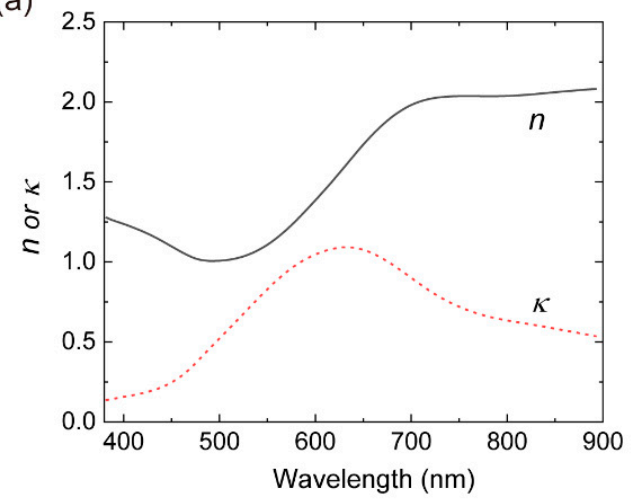

(b)

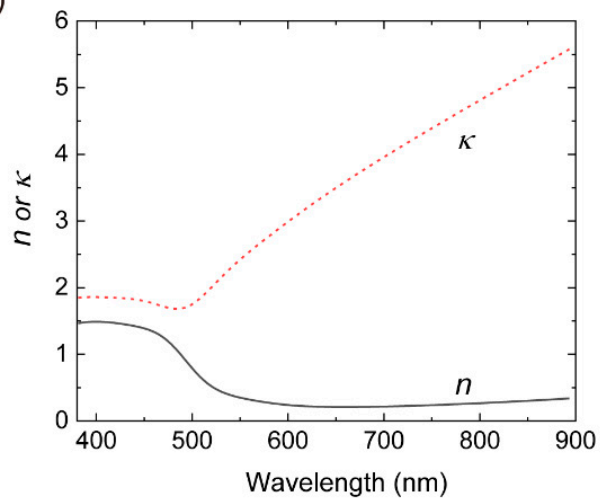

Figure 5. Refractive index $(n)$ and extinction coefficient $(\kappa)$ spectra of the O3MeOT (a) and vacuum-evaporated gold film (b).

The shapes of the refractive index and extinction coefficient spectra of the vacuumevaporated gold film (Figure 5b) were completely different compared to the O3MeOT film (Figure 5a). It was observed that above $500 \mathrm{~nm}$, the refractive index of the film was low, while its extinction coefficient was very high. This behavior is typical of metals. For common metals [15], the real part of the relative permittivity is less than zero at wavelengths longer than the wavelength corresponding to the plasma frequency of free electrons (Langmuir wavelength), and therefore, above the Langmuir wavelength, the refractive index has a low value. On the other hand, the extinction coefficient takes a very high value in the wavelength region that is longer than the Langmuir wavelength, resulting in a high specular reflectance above the Langmuir wavelength. These results confirmed that although the specular reflection spectral shapes of the O3MeOT and metallic gold films were similar (see Figure $4 \mathrm{~b}, \mathrm{~d}$ ), the mechanisms for developing these spectral shapes were completely different. Therefore, we confirmed that the lustrous color of the O3MeOT film is not induced by a mechanism based on Drude metallic response (the screening of electromagnetic waves by free electrons). Based on a series of experimental results in this study, we can conclude that the reason for the glossy appearance of the O3MeOT film is due to the fact that the O3MeOT molecules form compact lamellar crystallites in the film [10-12] and the crystallites develop very large optical constants (see Figure 5a), as has been speculated $[13,14]$.

\section{Conclusions}

In summary, it was revealed that the glossy appearance of the O3MeOT film is due to the reflection of light based on the very large values of the optical constants, as shown in Figure 5a. Thereby, this study concluded that the origin of the gold-like luster is not based on the structural color or free electrons. The finding of this study provides a basis for controlling the luster and color of oligomer films, and was concluded to be important from the perspective of color engineering. Moreover, the above finding relies on the concepts of molecular orientation and thus contributes to the development of organic electronics similar to those based on poly(3-alkylthiophene).

Supplementary Materials: The following are available online at https:/ /www.mdpi.com/article/10 .3390/coatings11070861/s1, Figure S1: Specular reflection spectrum of the O3MeOT film.

Author Contributions: Conceptualization, K.H. and M.K.; methodology, K.H.; investigation, M.K., M.T., T.M., K.S., R.S., and S.T.; resources, K.H.; data curation, M.K., M.T., S.T., and T.H.; writingoriginal draft preparation, K.H. and M.K.; writing-review and editing, K.H. and T.H; supervision, K.H.; project administration, K.H.; funding acquisition, K.H. All authors have read and agreed to the published version of the manuscript.

Funding: This research was funded by JSPS KAKENHI (Grant 20K05614 to K.H.).

Institutional Review Board Statement: Not applicable. 
Informed Consent Statement: Not applicable.

Data Availability Statement: Data is contained within the article and supplementary material.

Acknowledgments: The authors thank the Center for Analytical Instrumentation of Chiba University for reflection measurements and SEM observations.

Conflicts of Interest: The authors declare no conflict of interest.

\section{References}

1. Park, B.; Aiyar, A.; Park, M.S.; Srinivasarao, M.; Reichmanis, E. Conducting channel formation in poly (3-hexylthiophene) field effect transistors: Bulk to interface. J. Phys. Chem. C 2011, 115, 11719-11726. [CrossRef]

2. Yang, Y.; Hong, Y.; Wang, X. Utilizing the diffusion of fluorinated polymers to modify the semiconductor/dielectric interface in solution-processed conjugated polymer field-effect transistors. ACS Appl. Mater. Interfaces 2021, 13, 8682-8691. [CrossRef] [PubMed]

3. Milanovich, M.; Sarkar, T.; Popowski, Y.; Low, J.Z.; Campos, L.M.; Kenig, S.; Frey, G.L.; Amir, E. Enhancing P3HT/PCBM blend stability by thermal crosslinking using poly(3-hexylthiophene)-S,S-dioxide. J. Mater. Chem. C 2020, 8, 7698-7707. [CrossRef]

4. Grimsdale, A.C.; Chan, K.L.; Martin, R.E.; Jokisz, P.G.; Holmes, A.B. Synthesis of light-emitting conjugated polymers for applications in electroluminescent devices. Chem. Rev. 2009, 109, 897-1091. [CrossRef] [PubMed]

5. Murad, A.R.; Iraqi, A.; Aziz, S.B.; Abdullah, S.N.; Brza, M.A. Conducting Polymers for optoelectronic devices and organic Solar Cells: A Review. Polymers 2020, 12, 2627. [CrossRef] [PubMed]

6. Mazzio, K.A.; Luscombe, C.K. The future of organic photovoltaics. Chem. Soc. Rev. 2015, 44, 78-90. [CrossRef]

7. Lanzi, M.; Pierini, F. Efficient and thermally stable BHJ solar cells based on a soluble hydroxy-functionalized regioregular poly-dodecylthiophene. React. Funct. Polym. 2021, 158, 104803. [CrossRef]

8. Kawai, T.; Nakazono, M.; Yoshino, K. Effects of doping on the crystal structure of poly(3-alkylthiophene). J. Mater. Chem. 1992, 2, 903-906. [CrossRef]

9. Guay, J.; Kasai, P.; Diaz, A.; Wu, R.; Tour, J.M.; Dao, L.H. Chain-length dependence of electrochemical and electronic properties of neutral and oxidized soluble $\alpha, \alpha$-coupled thiophene oligomers. Chem. Mater. 1992, 4, 1097-1105. [CrossRef]

10. Tagawa, R.; Masu, H.; Itoh, T.; Hoshino, K. Solution-cast self-assembled films of perchlorate-doped oligo(3-methoxythiophene) showing a gold-like luster. RSC Adv. 2014, 4, 24053-24058. [CrossRef]

11. Takashina, Y.; Mitogawa, T.; Saito, K.; Hoshino, K. Chemical events in oligo(3-methoxythiophene) coating solutions and their effect on the goldlike coating film properties. Langmuir 2018, 34, 3049-3057. [CrossRef] [PubMed]

12. Takashina, Y.; Hoshino, K. Effect of $\pi-\pi$ interaction-induced secondary doping on the gold-like luster of oligo(3-methoxythiophene) cast films. Polym. J. 2019, 51, 591-599. [CrossRef]

13. Tachiki, M.; Tagawa, R.; Hoshino, K. Oligo(3-methoxythiophene)s as water-soluble dyes for highly lustrous gold- and bronze-like metal-effect coatings and printings. ACS Omega 2020, 5, 24379-24388. [CrossRef]

14. Tachiki, M.; Tsukada, S.; Hoshino, K. Effect of polymerization rate on the chemical and optical properties of solution-cast metal-like lustrous films of water-soluble 3-methoxythiophene oligomer dyes. Dyes Pigment. 2021, 190, 109302. [CrossRef]

15. Wooten, F. Optical Properties of Solids; Academic Press: New York, NY, USA, 1972.

16. Kohri, M.; Yanagimoto, K.; Kawamura, A.; Hamada, K.; Imai, Y.; Watanabe, T.; Ono, T.; Taniguchi, T.; Kishikawa, K. Polydopaminebased 3D colloidal photonic materials: Structural color balls and fibers from melanin-lke particles with polydopamine shell layers. ACS Appl. Mater. Interface 2018, 10, 7640-7648. [CrossRef]

17. Kohri, M.; Nannichi, Y.; Taniguchi, T.; Kishikawa, K. Biomimetic non-iridescent structural colormaterials from polydopamine black particles thatmimic melanin granules. J. Mater. Chem. C 2015, 3, 720-724. [CrossRef]

18. Okazawa, G.; Koida, K.; Komatsu, H. Categorical properties of the color term “GOLD”. J. Vis. 2011, 11, 1-19. [CrossRef] [PubMed]

19. Daira, T.; Omodani, M. Clarification of gold color recognition mechanism: A study on the effects of lighting condition. J. Imaging Soc. Jpn. 2011, 50, 498-502.

20. Tsuboi, T.; Nihira, K.; Gunji, T. A study on iridescent effect of tamamushi fabrics by hemispheric diffuse illuminator. J. Text. Mach. Soc. Jpn. 1975, 21, 46-54. [CrossRef]

21. Bernad, B.; Ferrero, A.; Strothkämper, C.; Campos, J.; Pons, A.; Quast, T.; Hauer, K.-O.; Schirmacher, A. Deviation of white diffuse reflectance standards from perfect reflecting diffuser at visible and near-infrared spectral ranges. Metrologia 2019, 56, 055005. [CrossRef]

22. Kim, S.; Iwakiri, T.; Yagi, R.; Ogata, T.; Kurihara, S. Fabrication of wide angle structural color with the patchy multi-bilayered films. Mol. Cryst. Liquid Cryst. 2017, 644, 36-43. [CrossRef]

23. Kohri, M.; Yamazaki, S.; Kawamura, A.; Taniguchi, T.; Kishikawa, K. Bright structural color films independent of background prepared by the dip-coating of biomimetic melanin-like particles having polydopamine shell layers. Colloid Surf. A Physicochem. Eng. Asp. 2017, 532, 564-569. [CrossRef]

24. Katagiri, K.; Tanaka, Y.; Uemura, K.; Inumaru, K.; Seki, T.; Takeoka, Y. Structural color coating films composed of an amorphous array of colloidal particles via electrophoretic deposition. NPG Asia Mater. 2017, 9, e355. [CrossRef]

25. Ohnuki, R.; Sakai, M.; Takeoka, Y.; Yoshioka, S. Optical Characterization of the Photonic Ball as a Structurally Colored Pigment. Langmuir 2020, 36, 5579-5587. [CrossRef] 
26. Wu, S.; Huang, B.; Wu, Y.; Meng, Z.; Zhang, S. Reflection and transmission two-way structural colors. Nanoscale 2020, 12, 11460-11467. [CrossRef]

27. Yamada, H.; Kukino, M.; Wang, Z.A.; Miyabara, R.; Fujimoto, N.; Kuwabara, J.; Matsuishi, K.; Kanbara, T. Preparation and characterization of green reflective films of polyaniline analogs containing azobenzene units J. Appl. Polym. Sci. 2015, 132, 41275. [CrossRef]

28. Kondo, Y.; Matsumoto, A.; Fukuyasu, K.; Nakajima, K.; Takahashi, Y. Gold-colored organic crystals of an azobenzene derivative. Langmuir 2014, 30, 4422-4426. [CrossRef] [PubMed]

29. Takeoka, Y.; Yoshioka, S.; Takano, A.; Arai, S.; Nueangnoraj, K.; Nishihara, H.; Teshima, M.; Ohtsuka, Y.; Seki, T. Production of colored pigments with amorphous arrays of black and white colloidal particles. Angew. Chem. Int. Ed. 2013, 52, 7261-7265. [CrossRef]

30. Kawamura, A.; Kohri, M.; Morimoto, G.; Nannichi, Y.; Taniguchi, T.; Kishikawa, K. Full-color biomimetic photonic materials with iridescent and non-iridescent structural colors. Sci. Rep. 2016, 6, 33984. [CrossRef] [PubMed]

31. Morisue, M.; Hoshino, Y.; Shimizu, M.; Tomita, S.; Sasaki, S.; Sakurai, S.; Hikima, T.; Kawamura, A.; Kohri, M.; Matsui, J.; et al. A metal-lustrous porphyrin foil. Chem. Commun. 2017, 53, 10703-10706. [CrossRef] 